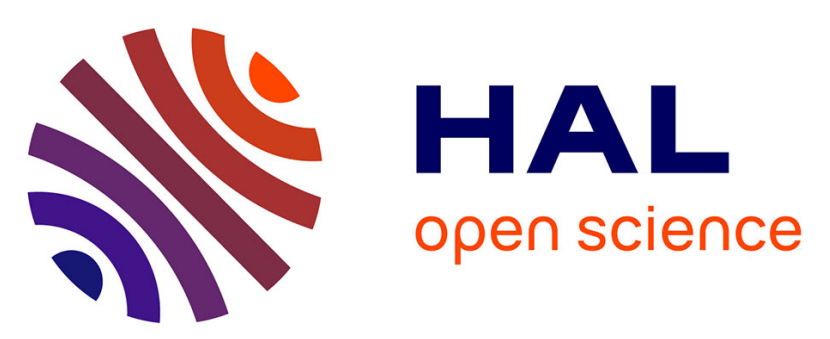

\title{
Balance, barycentremetry and external shape analysis in idiopathic scoliosis: What can the physician expect from it?
}

Tristan Langlais, Claudio Vergari, Grégoire Rougereau, Laurent Gajny, Ayman Assi, Ismat Ghanem, Jean Dubousset, Raphaël Vialle, Raphaël Pietton, Wafa Skalli

\section{To cite this version:}

Tristan Langlais, Claudio Vergari, Grégoire Rougereau, Laurent Gajny, Ayman Assi, et al.. Balance, barycentremetry and external shape analysis in idiopathic scoliosis: What can the physician expect from it?. Medical Engineering \& Physics, 2021, 94, pp.33-40. 10.1016/j.medengphy.2021.06.004 . hal-03288128

\section{HAL Id: hal-03288128 \\ https://hal.science/hal-03288128}

Submitted on 16 Jul 2021

HAL is a multi-disciplinary open access archive for the deposit and dissemination of scientific research documents, whether they are published or not. The documents may come from teaching and research institutions in France or abroad, or from public or private research centers.
L'archive ouverte pluridisciplinaire HAL, est destinée au dépôt et à la diffusion de documents scientifiques de niveau recherche, publiés ou non, émanant des établissements d'enseignement et de recherche français ou étrangers, des laboratoires publics ou privés. 


\title{
Balance, barycentremetry and external shape analysis in idiopathic scoliosis: What can the physician expect from it?
}

\author{
Tristan Langlais ${ }^{\mathrm{a}, \mathrm{b}, \mathrm{c}, *}$, Claudio Vergari ${ }^{\mathrm{c}}$, Grégoire Rougereau ${ }^{\mathrm{a}}$, Laurent Gajny ${ }^{\mathrm{c}}$, Ayman Assi $^{\mathrm{d}}$, \\ Ismat Ghanem $^{\mathrm{d}}$, Jean Dubousset ${ }^{\mathrm{c}}$, Raphaël Vialle ${ }^{\mathrm{a}, \mathrm{e}}$, Raphaël Pietton ${ }^{\mathrm{a}}$, Wafa Skalli ${ }^{\mathrm{c}}$ \\ ${ }^{a}$ Department of Pediatric Orthopedics, Armand-Trousseau Hospital, Sorbonne University, 26 avenue du Dr. Arnold Netter, Paris 75012, France \\ ${ }^{\mathrm{b}}$ Children's hospital, Orthopedics Department, Purpan, Toulouse University, Toulouse, France \\ ${ }^{c}$ Arts et Métiers Institute of Technology, Université Sorbonne Paris Nord, IBHGC - Institut de Biomécanique Humaine Georges Charpak, HESAM Université, Paris 75013, \\ France \\ d Laboratory of Biomechanics and Medical Imaging, Faculty of Medicine, University of Saint-Joseph in Beirut, Beirut, Lebanon \\ e The MAMUTH Hospital University Department for Innovative Therapies in Musculoskeletal Disease Sorbonne University, Paris, France
}

A R T I C L E I N F O

Keywords:

Scoliosis

Peadiatric

Idiopathic

Barycentremetry

External shape

\section{A B S T R A C T}

Objective: Our objective was to establish a corridor of normality for the external shape 3D parameters and then to assess these variables in adolescent idiopathic scoliosis (AIS).

Methods: Adolescent with mild and severe AIS were included prospectively, as well as a control group of asymptomatic subjects. A quasi-automatic 3D reconstruction of the spine and manual 3D reconstruction of the external envelope was performed from biplanar radiography. The center of mass position, the axial interseg-mental moment resulting at the apex and junctional vertebrae, and the coronal trunk balance were automatically computed. A normality corridor of asymptomatic subjects was calculated as the range $\left[5^{\text {th }}-95^{\text {th }}\right.$ percentiles $]$ for external shape parameters at each vertebral level.

Results: Forty-one asymptomatic subjects ( 19 females; 22 males; 21 yo, SD=4) and sixty AIS (56 females; 4 males; 13 years old, $S D=1.9 ; 30$ mild and 30 severe; 34 thoracic curves and 26 thoraco-lumbar or lumbar curves) were included. All parameters based on the external shape showed differences between AIS and controls, as well as between mild and severe scoliosis. For instance, the intersegmental moment applied to the upper junctional vertebra was above the $95^{\text {th }}$ percentile of controls in $70 \%$ of AIS patient. The percentage of severe patients showing parameters higher than the normality corridor was significantly higher than mild patients $(\mathrm{p}<0.0001)$. Conclusions: The analysis of center of mass, vertebral intersegmental moment and coronal trunk balance pa-rameters appear to be relevant in characterizing the $3 \mathrm{D}$ deformity of adolescent idiopathic scoliosis. The upper junctional intersegmental moment seems to be able to distinguish the different stages of curvature severity.

\section{Introduction}

Idiopathic scoliosis is a 3-dimensional (3D) spinal deformity of uncertain etiology defined in the coronal plane by a Cobb angle of at least $10^{\circ}$ and axial vertebral rotation [1]. 3D reconstruction of the spine from low-dose biplanar X-rays has made it possible to quantify the deformation in a standing posture using new objective biomechanical markers (e.g. intervertebral axial rotation, torsion index) [2]. These markers can help in the characterization of scoliosis and its potential progression, as well as in the planning of treatment and analysis of outcomes $[2,3]$.
Concurrent with localized bone deformity, progressive idiopathic scoliosis can lead to postural imbalance and thus disturb the overall balance of the trunk and waist [4]. Recently, preliminary studies have investigated biomechanical factors resulting from external shape reconstruction such as the center of mass or the intersegmental moment $[5,6]$. Furthermore, the feasibility of assessing center of mass using 3D reconstruction of the external envelope from biplanar $\mathrm{x}$-rays was demonstrated, reporting an uncertainty within $6 \mathrm{~mm}$ (in terms of twice the standard deviation) when compared to a force plate [5]. Differences have been found in scoliotic patients and more precisely at the

Abbreviations: 3D, 3 dimensional; AIS, adolescent idiopathic scoliosis; SD, standart deviation; CoM, center of mass; BMI, body mass index; T, thoracic curve scoliosis; TLL, thoraco-lumbar or lumbar scoliosis; y, years; N, number of subjects.

* Corresponding author.

E-mail address: tristanlanglais@yahoo.fr (T. Langlais). 


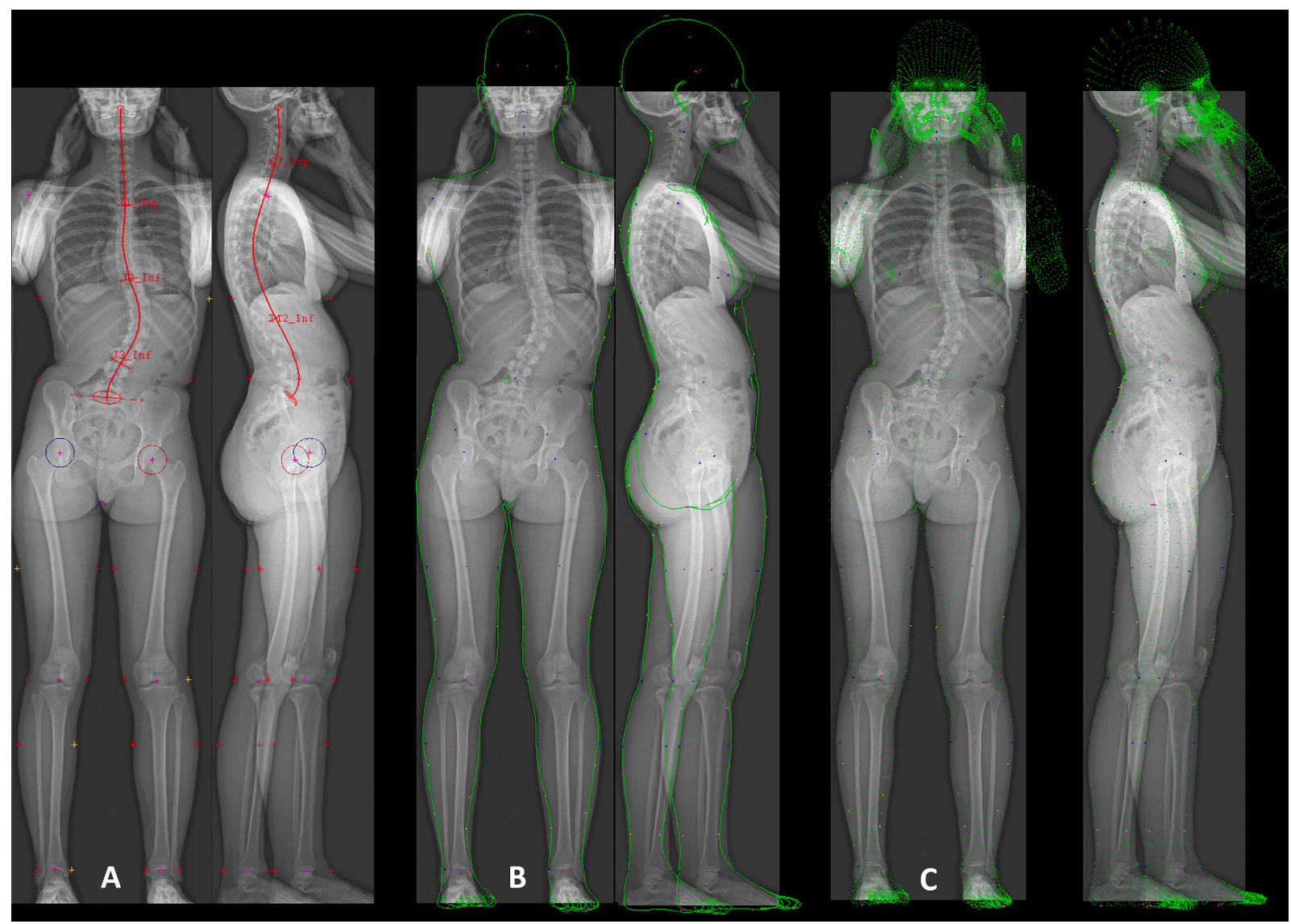

Fig. 1. Example of spinal and external shape reconstruction.

junctional level [6], but the clinical relevance of external shape analysis, and on the many parameters that it can provide, has not been evaluated yet. How do these parameters adjust depending on the severity and/or location of the curvature? Can they guide the physician in the diagnosis or therapeutic assessment? In particular, this analysis might help corroborate the hypothesis that scoliosis is a decompensation of the spine that starts in the transverse plane. The hypothesis of this work was that barycentremetry and external shape analysis is relevant in characterizing the 3D deformity of adolescent idiopathic scoliosis (AIS). Our objective was to establish a corridor of normality for the 3D parameters and then to assess these variables in a scoliotic population according to curve severity and location.

\section{Materials and methods}

\subsection{Subjects}

Data were collected prospectively from orthopedic department within follow-up clinical investigation for the scoliosis group (group S) and as part of the research protocol for the asymptomatic group (group A). Parents, children and adults were informed about the protocol and consented to participating before inclusion. Parents or adults signed informed consent, which was approved by the ethics committee (C.P.P. Ile de France VI 6001).

Asymptomatic young adults were included in group A if they had no history of spinal disease. A systematic clinical examination was performed by a spine surgeon to rule out any diagnosis of scoliosis for these subjects. A pathognomonic scoliosis sign, a rib hump and other clinical signs like dorsal pain, asymmetry of the shoulders or pelvic asymmetry were criteria for exclusions.

Adolescent with idiopathic scoliosis Lenke [7] 1, 3 and 5, aged less than 18 years (y), with a main Cobb angle between 10 and $25^{\circ}$ (mild scoliosis) and superior than $35^{\circ}$ (severe scoliosis) were included. Patient with congenital, syndromic or neuro-muscular scoliosis, early onset scoliosis (less than 10 years), supernumerary vertebrae, a transitional anomaly, or history of spine surgery were excluded. Weight, height and body mass index were measured for each subject. All patients underwent a low dose biplanar X-ray (EOS system, EOS Imaging, Paris, France) at inclusion, in the standardized free-standing position [8]. Patients who did not respect this position were excluded (arms held too high, too low or asymmetrically, obvious leaning forwards or backwards, etc.). Group Scoliosis (S) was divided for analysis into two groups according to curve severity: "mild" scoliosis defined by a Cobb angle between $10^{\circ}$ et $25^{\circ}$, European Risser sign [9] from 0 to 2 and no previous treatment, whereas "severe" scoliosis was defined by a Cobb angle higher than $35^{\circ}$. Patients were also grouped by main curve location: main thoracic curve scoliosis grouped together Lenke 1 and $3(\mathrm{~T})$ whereas thoraco-lumbar or lumbar scoliosis corresponded to Lenke 5 (TLL).

\section{2. $3 D$ spinal reconstruction}

A quasi-automatic 3D reconstruction of the spine was performed with a previously validated technique $[3,10]$. Briefly, the operator selected a few anatomical landmarks on the frontal and lateral radiographs: sacral plate, left and right acetabula, the spinal midline through the center of all vertebral bodies from the odontoid apophysis of C2 to L5 lower endplate. The upper endplate of C7 and lower endplate of T12 were also selected in the lateral view, while the two endplates delimiting the main scoliotic curve were selected in the frontal view. The junctional levels of the main curve were defined to obtain the maximization of Cobb angle, and they were often characterized by a local discontinuity of vertebral axial rotation (i.e., a sudden change of vertebral axial 


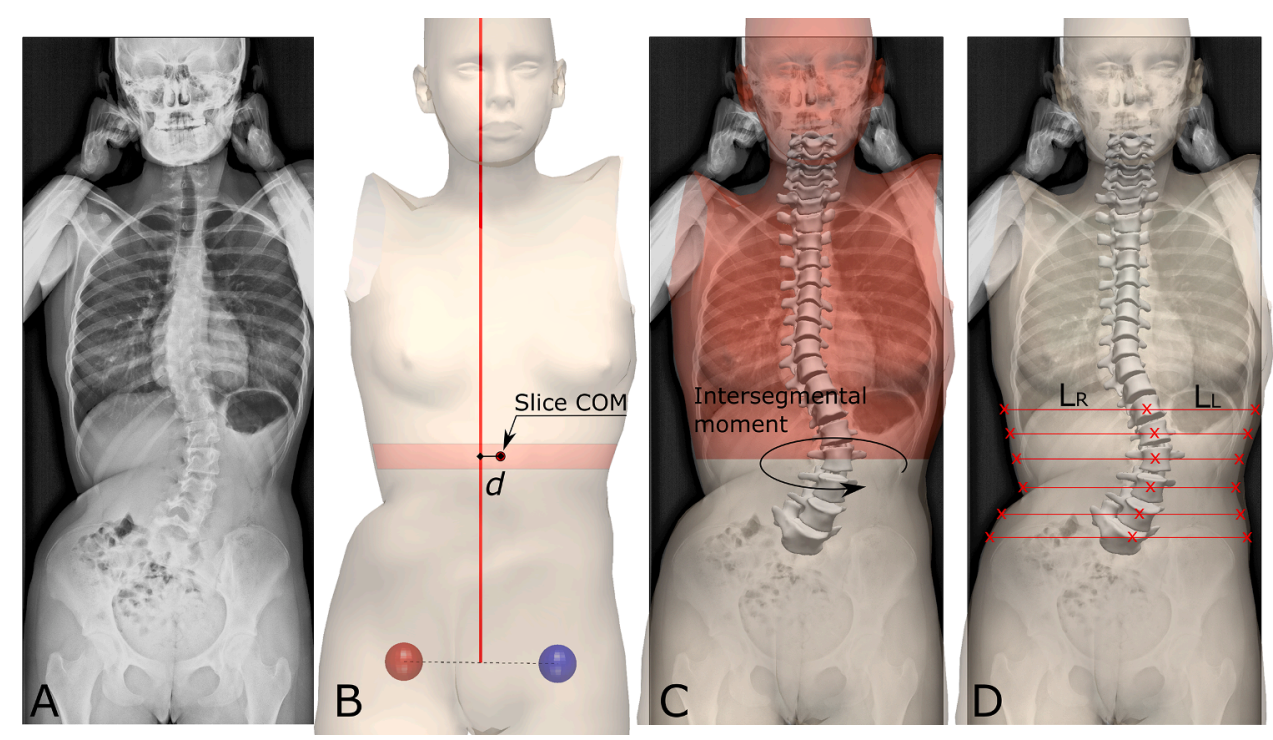

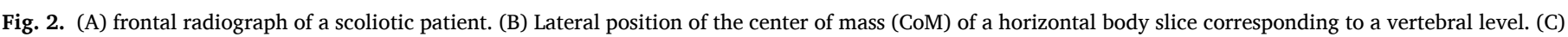

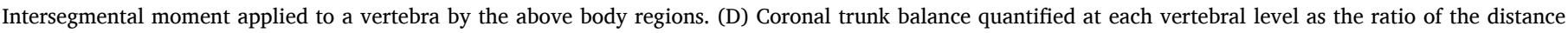
between the vertebra and the left and right sides of the body.

orientation). An automatic algorithm provided an initial solution of 3D reconstruction, on which the operator could perform fast manual adjustment of some key vertebrae (the apex, junctions and the adjacent to the junctions) to improve accuracy (Fig. 1A). The 3D reconstruction allowed for the automatic computation of classical spinopelvic parameters, such as Cobb angle, OD-HA, T1-T12 and T4-T12 kyphosis, L1-S1 lordosis, pelvic incidence (PI), pelvic tilt (PT) and sacral slope (SS).

\section{3. $3 D$ external shape reconstruction}

External shape (head, thorax, abdomen, arms, legs, and feet) was reconstructed using a validated manual technique [11]. The procedure takes 15 minutes and consists in 2 steps:

1) A first set of 49 control points included the location of the crotch, the midpoint of the L4-L5 intervertebral disc, and 8 joint centers in order to scale the body envelope pattern on the coronal and sagittal radiographs of the subjects. These points were used to deform a generic template to fit the patient-specific morphology, and the external shape was projected onto both radiographs (Fig. 1A).

2) The second set included 77 skin points for a fine deformation of the template. These points were disposed on the body parts of high shape variation between individuals, such as the waist, which depends on subjects' weight and muscle structures. By manually moving each of these skin control points, the template could be adjusted to match the contour from the frontal and lateral radiographs (Fig. 1B). Finally, a second well-trained operator performed a quality control procedure, and errors were adjusted if necessary (Fig. 1C).

\subsection{External shape parameters}

Body segments weights were calculated according to a recent estimation of segmental mass density [12]. Then, three parameters resulting from the reconstruction were automatically computed:

\section{1) The center of mass (CoM) position}

Horizontal slices of the external envelope were virtually cut at each vertebral level. The lateral CoM of each slice was computed to calculate its distance from the vertical line passing through the middle of the interacetabular axis in the coronal plane. This distance was calculated at all vertebral levels in asymptomatic controls, in order to define a normality corridor, and at specific vertebral levels in scoliotic patients: apical, upper junctional and lower junctional [6]. This parameter represents the lateral mass displacement at specific regions (Fig. 2B). Furthermore, the position of the global trunk CoM relatively to the pelvic acetabula was computed.

\section{1) Intersegmental moment}

Intersegmental moment was the torsional moment applied to each vertebra (apical, upper and lower junction) as a result of its lateral displacement and inclination in the sagittal plane, due to the mass of the body above the vertebra and the position of this segment's center of mass [6] (Fig. 2C).

\section{1) Coronal trunk balance}

Coronal trunk balance was quantified using the lateral offset of the envelope. This parameter was computed at each vertebral level below T10 as follows: a series of horizontal lines were defined in the coronal plane, passing through the center of each vertebral body. The intersections between these lines and the externals envelope were marked. Finally, the ratio of the distances between the vertebral body and the left and right intersection were computed automatically. Furthermore, this ratio was defined at apical and lower junctional if these vertebral levels were below T10 (Fig. 2D). This parameter represents the local lateral asymmetry of the external envelope in the lumbar region.

\subsection{Statistical analysis}

Reliability of the novel parameters (lateral center of mass position, spinal intersegmental moment and lateral offset of the envelope) was estimated with a Monte Carlo procedure: the 3D reconstruction of each patient was virtually modified by adding uncertainty to the vertebral orientations and positions, as well as on the position of the CoM. The uncertainty was randomly picked from a normal distribution of errors based on previous evaluations of local uncertainty $[5,10]$. This was repeated 50 times for each patient, for a total of 5050 simulations, which allowed to estimate a standard deviation of uncertainty for each parameter. Non-parametric statistical tests were used because not all variables were normally distributed (Lilliefors normality test). In order 
Table 1

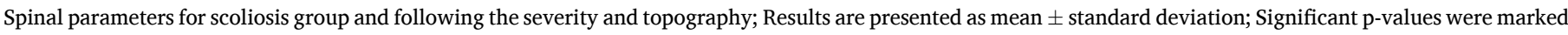
in bold. p-value ${ }_{1}$ and ${ }_{2}$ represents respectively the significance of the difference between severity groups and scoliosis localization groups.

\begin{tabular}{|c|c|c|c|c|c|c|c|}
\hline & Scoliosis $(\mathrm{N}=60)$ & Mild scoliosis $(\mathrm{N}=30)$ & Severe scoliosis $(\mathrm{N}=30)$ & $p$-value ${ }_{1}$ & $\mathrm{~T}$ curve $(\mathrm{N}=34)$ & TLL curve $(\mathrm{N}=26)$ & p-value 2 \\
\hline Main Cobb angle $\left(^{\circ}\right)$ & $36 \pm 18$ & $20 \pm 6$ & $53 \pm 9$ & $<0.0001$ & $37 \pm 17$ & $36 \pm 20$ & 0.7 \\
\hline OD-HA $\left(^{\circ}\right)$ & $1.6 \pm 1$ & $1.2 \pm 0.7$ & $1.9 \pm 1.2$ & 0.2 & $1.4 \pm 0.9$ & $1.8 \pm 1.2$ & 0.4 \\
\hline $\mathrm{T} 1-\mathrm{T} 12\left(^{\circ}\right)$ & $32 \pm 16$ & $32 \pm 19$ & $33 \pm 11$ & 0.7 & $30 \pm 17$ & $37 \pm 13$ & 0.2 \\
\hline $\mathrm{T} 4-\mathrm{T} 12\left({ }^{\circ}\right)$ & $22 \pm 16$ & $24 \pm 17$ & $20 \pm 15$ & 0.2 & $18 \pm 14$ & $27 \pm 16$ & 0.05 \\
\hline L1-L5 $\left(^{\circ}\right)$ & $41 \pm 20$ & $39 \pm 24$ & $43 \pm 13$ & 0.9 & $39 \pm 24$ & $44 \pm 11$ & 0.7 \\
\hline PI $\left({ }^{\circ}\right)$ & $43 \pm 11$ & $40 \pm 7$ & $46 \pm 13$ & 0.07 & $44 \pm 11$ & $42 \pm 11$ & 0.7 \\
\hline $\mathrm{PT}\left({ }^{\circ}\right)$ & $4 \pm 7$ & $3 \pm 7$ & $5 \pm 7$ & 0.5 & $4 \pm 7$ & $4.6 \pm 8$ & 0.6 \\
\hline SS $\left(^{\circ}\right)$ & $39 \pm 9$ & $36 \pm 8$ & $41 \pm 9$ & 0.06 & $40 \pm 9$ & $38 \pm 9$ & 0.3 \\
\hline
\end{tabular}

Table 2

Normality corridors for parameters of external shape analysis. Results are presented such as median [ $5^{\text {th }}-95^{\text {th }}$ percentile]; na $=$ not applicable; CoM: center of mass of body slices at each vertebral level.

\begin{tabular}{llll}
\hline $\begin{array}{l}\text { Vertebrae } \\
\text { level }\end{array}$ & $\begin{array}{l}\text { Intersegmental moment } \\
{[\mathrm{N} / \mathrm{m}]}\end{array}$ & $\begin{array}{l}\text { Lateral CoM } \\
\text { position }[\mathrm{mm}]\end{array}$ & $\begin{array}{l}\text { Coronal trunk } \\
\text { balance }\end{array}$ \\
\hline T1 & $0.07[0-0.29]$ & $6.82[0.34-17.27]$ & na \\
T2 & $0.07[0-0.33]$ & $7.62[0.72-24.15]$ & na \\
T3 & $0.23[0-0.87]$ & $8.96[0.40-20.83]$ & na \\
T4 & $0.34[0.06-1.58]$ & $8.67[0.98-20.57]$ & na \\
T5 & $0.34[0-1.31]$ & $5.86[0.04-14.56]$ & na \\
T6 & $0.44[0.05-1.51]$ & $5.96[0.44-12.72]$ & na \\
T7 & $0.42[0.08-1.98]$ & $5.72[0.37-14.08]$ & na \\
T8 & $0.49[0.03-2]$ & $6.13[0.70-12.30]$ & na \\
T9 & $0.45[0.01-1.65]$ & $6.36[0.87-12]$ & na \\
T10 & $0.45[0-1.23]$ & $6.31[0.25-13.06]$ & na \\
T11 & $0.48[0.01-1.32]$ & $6.26[0.41-13.09]$ & $0.92[0.80-$ \\
& & & $0.98]$ \\
T12 & $0.48[0.01-1.28]$ & $6.10[0.04-12.98]$ & $0.92[0.81-$ \\
& & & $0.99]$ \\
L1 & $0.44[0.06-0.9]$ & $5.54[0.53-11.14]$ & $0.91[0.81-$ \\
& & & $0.99]$ \\
L2 & $0.48[0.06-1.23]$ & $4.75[0.43-11.23]$ & $0.93[0.82-$ \\
& & & $0.98]$ \\
L3 & $0.23[0.02-1.09]$ & $4.1[0.31-12.1]$ & $0.94[0.83-1]$ \\
L4 & $0.29[0-0.9]$ & $3.17[0.09-9.82]$ & $0.95[0.84-$ \\
& & $2.53[0.14-10.12]$ & $0.99]$ \\
L5 & $0.40[0.03-1.45]$ & & $0.97[0.86-$ \\
& & & \\
\hline
\end{tabular}

to compare spinal and external shape parameters according groups, the Mann-Whitney's test was applied. In order to compare the relationship between spinal and external shape parameters, Spearman's correlation was applied. A normality corridor of asymptomatic subjects was calculated as the range $\left[5^{\text {th }}-95^{\text {th }}\right.$ percentiles] for external shape parameters at each vertebrae level. The number of scoliotic children having their external shape parameters higher than the corridor's limits was reported and their values were defined as abnormal. Statistical analysis was performed using R software (v3.6.3). Significance was set at 0.05.

\section{Results}

\subsection{Subjects}

Forty-one asymptomatic subjects (19 females; 22 males) were included with a mean age of $21 \mathrm{y}$ ( $\mathrm{SD}=4$; from 10 to $31 \mathrm{y}$ ) and a mean BMI of 21.7 kg.m ${ }^{-1}$ ( $\mathrm{SD}=2$; from 16.7 to $26.4 \mathrm{~kg} \cdot \mathrm{m}^{-1}$ ).

Sixty adolescent idiopathic scoliosis ( 56 females; 4 males) were included with mean age of $13 \mathrm{y}$ ( $\mathrm{SD}=1.9$; from 10 to $18 \mathrm{y}$ ). The mean BMI was $18.5 \mathrm{~kg} . \mathrm{m}^{-1}\left(\mathrm{SD}=0.1\right.$; from 13.3 to $\left.27.3 \mathrm{~kg} \cdot \mathrm{m}^{-1}\right)$.

Thirty AIS (27 females and 3 males; $12 \mathrm{y}$ with $\mathrm{SD}=1.8 ; 17.8 \mathrm{~kg} . \mathrm{m}^{-1}$ with $\mathrm{SD}=3$; 13 Lenke 1, 4 Lenke 3 and 13 Lenke 5) were classified as mild scoliosis while 30 AIS were severe (28 females and 2 males; $15 y$ with $\mathrm{SD}=1.4 ; 19.1 \mathrm{~kg} \cdot \mathrm{m}^{-1}$ with $\mathrm{SD}=3 ; 13$ Lenke 1,4 Lenke 3 and 13 Lenke 5).

Thirty-four AIS (33 females and 1 male; $13.4 y$ with $S D=6 ; 18.8 \mathrm{~kg}$.
Table 3

Parameters related to the body external shape in scoliotic patients (mean \pm standard deviation). CoM: center of mass.

\begin{tabular}{|c|c|c|c|c|}
\hline \multirow{5}{*}{$\begin{array}{l}\text { Lateral CoM position } \\
\text { [mm] }\end{array}$} & & $\begin{array}{l}\text { Vertebral level } \\
\text { Upper } \\
\text { junctional }\end{array}$ & Apex & $\begin{array}{l}\text { Lower } \\
\text { junctional }\end{array}$ \\
\hline & Mild & $7.8 \pm 4.5$ & $\begin{array}{l}7.3 \pm \\
4.8\end{array}$ & $6.4 \pm 4.5$ \\
\hline & Severe & $15.7 \pm 10.2$ & $\begin{array}{l}17.3 \pm \\
9.6\end{array}$ & $17.5 \pm 9$ \\
\hline & $\mathrm{T}$ curve & $9.2 \pm 6.5$ & $\begin{array}{l}10.8 \pm \\
8.7\end{array}$ & $12.1 \pm 10$ \\
\hline & $\begin{array}{l}\text { TLL } \\
\text { curve }\end{array}$ & $14.9 \pm 10.2$ & $\begin{array}{l}14.2 \pm \\
9.3\end{array}$ & $11.7 \pm 6.5$ \\
\hline \multirow[t]{4}{*}{$\begin{array}{l}\text { Intersegmental } \\
\text { moment }\end{array}$} & Mild & $1.4 \pm 0.7$ & $\begin{array}{l}0.6 \pm \\
0.5\end{array}$ & $0.6 \pm 0.5$ \\
\hline & Severe & $4.6 \pm 1.9$ & $1.6 \pm 1$ & $2.6 \pm 1.5$ \\
\hline & $\mathrm{T}$ curve & $3.2 \pm 2.2$ & $1 \pm 1$ & $1.8 \pm 1.6$ \\
\hline & $\begin{array}{l}\text { TLL } \\
\text { curve }\end{array}$ & $2.7 \pm 1.9$ & $1.2 \pm 1$ & $1.3 \pm 1.2$ \\
\hline \multirow[t]{4}{*}{ Coronal trunk balance } & Mild & $0.9 \pm 0.1$ & $\begin{array}{l}0.9 \pm \\
0.1\end{array}$ & $0.9 \pm 0.1$ \\
\hline & Severe & $0.8 \pm 0.2$ & $\begin{array}{l}0.7 \pm \\
0.1\end{array}$ & $0.8 \pm 0.1$ \\
\hline & T curve & $0.9 \pm 0.1$ & $\begin{array}{l}0.9 \pm \\
0.1\end{array}$ & $0.8 \pm 0.1$ \\
\hline & $\begin{array}{l}\text { TLL } \\
\text { curve }\end{array}$ & $0.8 \pm 0.1$ & $\begin{array}{l}0.8 \pm \\
0.1\end{array}$ & $0.8 \pm 0.1$ \\
\hline
\end{tabular}

$\mathrm{m}^{-1}$ with $\mathrm{SD}=3$; mean main Cobb angle $=37.7^{\circ}$ with $\mathrm{SD}=17.7$ ) had a thoracic main curve while 26 AIS were thoracolumbar or lumbar (22 female and 4 male; $13.7 y$ with $\mathrm{SD}=1.9 ; 18.4 \mathrm{~kg} \cdot \mathrm{m}^{-1}$ with $\mathrm{SD}=2.4$; mean main Cobb angle $=35.7^{\circ}$ with $\mathrm{SD}=20.3$ ).

\subsection{Spinopelvic parameters}

In asymptomatic controls, the average OD-HA was $0.8^{\circ}(\mathrm{SD}=0.6) \mathrm{T} 1$ T12 kyphosis of $48^{\circ}(\mathrm{SD}=10.7)$, T4-T12 kyphosis of $34.2^{\circ}(\mathrm{SD}=10)$, L1$\mathrm{S} 1$ lordosis of $44.7^{\circ}(\mathrm{SD}=11.5)$, pelvic incidence of $49.2^{\circ}(\mathrm{SD}=9.5)$, pelvic tilt of $8.4^{\circ}(\mathrm{SD}=5.7)$ and sacral slope of $39.8^{\circ}(\mathrm{SD}=8.5)$. Spinopelvic parameters in scoliosis group were described in Table 1 .

\subsection{Reliability}

The uncertainty did not exceed $0.8 \mathrm{~mm}$ for the lateral position of CoM at all vertebral levels, $0.5 \mathrm{~N} / \mathrm{m}$ for the intersegmental moment and 0.1 for the coronal trunk balance.

\subsection{External body shape parameters}

The normality corridors for the parameters related to external body shape were reported in Table 2 and values for scoliotic patients in Table 3.

The lateral position of the CoM was abnormal in $32 \%(\mathrm{~N}=19 / 60)$ of upper junctional vertebrae, $42 \%(\mathrm{~N}=25 / 60)$ of apical and $43 \%(\mathrm{~N}=26 /$ $60)$ in lower junctional vertebrae, even though the average values were 


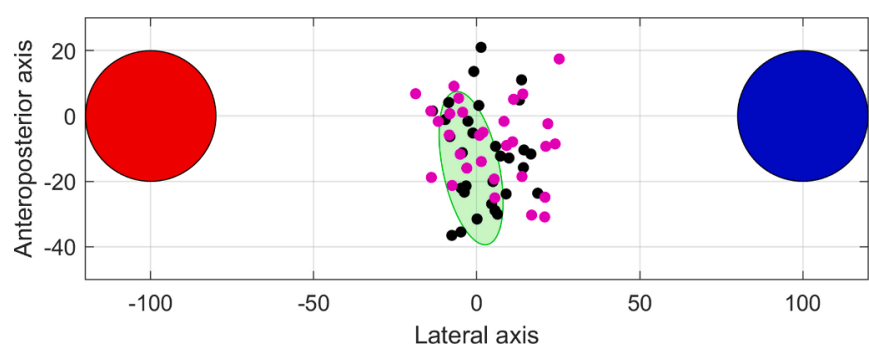

Fig. 3. Top view of the position of the CoM in mild (black) and severe scoliosis (pink) relative to its position in asymptomatic controls (green area, representing the $95^{\text {th }}$ percentile). The red and blue circles represent the left and right pelvic acetabula, respectively. The distance between acetabula was normalized to 200 , in order to place all patients in a common anatomical scale.

similar between AIS and asymptomatic controls $(\mathrm{p}=0.37)$. Upper junctional and apical lateral CoM position values are higher in TLL than in T group $(\mathrm{p}=0.01)$. When the global trunk CoM in asymptomatic subjects was analyzed in 3D, the $95^{\text {th }}$ percentile of normality corridor, as viewed from a top view, corresponded to a small ellipse of in the middle of the pelvic acetabula (Fig. 3). In this representation, the global trunk CoM of $60 \%(\mathrm{~N}=18 / 30)$ severe patients and $53 \%(\mathrm{~N}=16 / 30)$ mild patients fell outside this corridor.

The intersegmental moment applied to the upper junctional vertebra was abnormal in $70 \%(\mathrm{~N}=48 / 60)$ of scoliosis patients, while less than $50 \%$ in apex and lower junctional vertebrae were above $(\mathrm{p}<0.0001)$. These results were confirmed by a subgroup analysis according to curve's severity (Fig. 4).

Thirty-eight percent of scoliosis subjects $(\mathrm{N}=10 / 60)$ was abnormal for the apical coronal trunk balance and $45 \%(\mathrm{~N}=21 / 60)$ for lower junctional $(\mathrm{p}=0.41)$. Abnormal apical coronal trunk balance values were of $60 \%(\mathrm{~N}=6 / 10)$ in severe scoliosis (versus $25 \%$ in mild) and $43 \%$ $(\mathrm{N}=9 / 21)$ in TLL (versus $17 \%$ in $\mathrm{T}$ ).

Lateral CoM position and intersegmental moment were correlated angle, and the lateral CoM position was also correlated to OD-HA (Fig.

$5)$.

\section{Discussion}

In the monitoring of idiopathic scoliosis, the physician endeavors to use objective, reproducible, reliable and minimally invasive criteria to detect progressive scoliosis and in some cases to assess its treatment. In addition to the clinical and skeletal maturation criteria described initially by Duval Beaupère $[13,14]$, the clinician can use biomechanical parameters. The pioneering work of Duval Beaupère et al. showed that the $2 \mathrm{D}$ centre of mass study is related to the sagittal curvatures and pelvic parameters of young healthy patients [15]. Recently, further work has shown that the determination of the anatomical connection of the individual gravity is thus of primary importance for the evaluation of sagittal balance [16]. From our results, barycentremetry and external shape analysis seems to be relevant in characterizing the 3D deformity of adolescent idiopathic scoliosis for various reason. Longitudinal studies are under way to determine whether the proposed approach could lead to a reliable objective prediction of the curve's progression and enable clinical follow-up.

The first relevant finding is that the lateral center of mass position and the coronal trunk balance factors increase with the curve severity, independently of the curve location. This is not surprising that clinical postural imbalance is radiographically translated by alterations of these factors. In this sense, a preliminary study had demonstrated a correlation between imbalance and the distance between the plumb line and the gravity line in biplanar X-rays [5]. In this study, a correlation between OD-HA and the center of mass position was found. The posture imbalance can thus be quantified and could help the physician to quantitatively monitor the curve progression, but also to assess the therapeutic outcomes obtained by brace or spinal fusion correction. Sagittal balance was not analyzed in the present work because while scoliotic subjects often present a characteristic flat back, the also maintain a good sagittal alignment, with minimal imbalance, thanks to

A
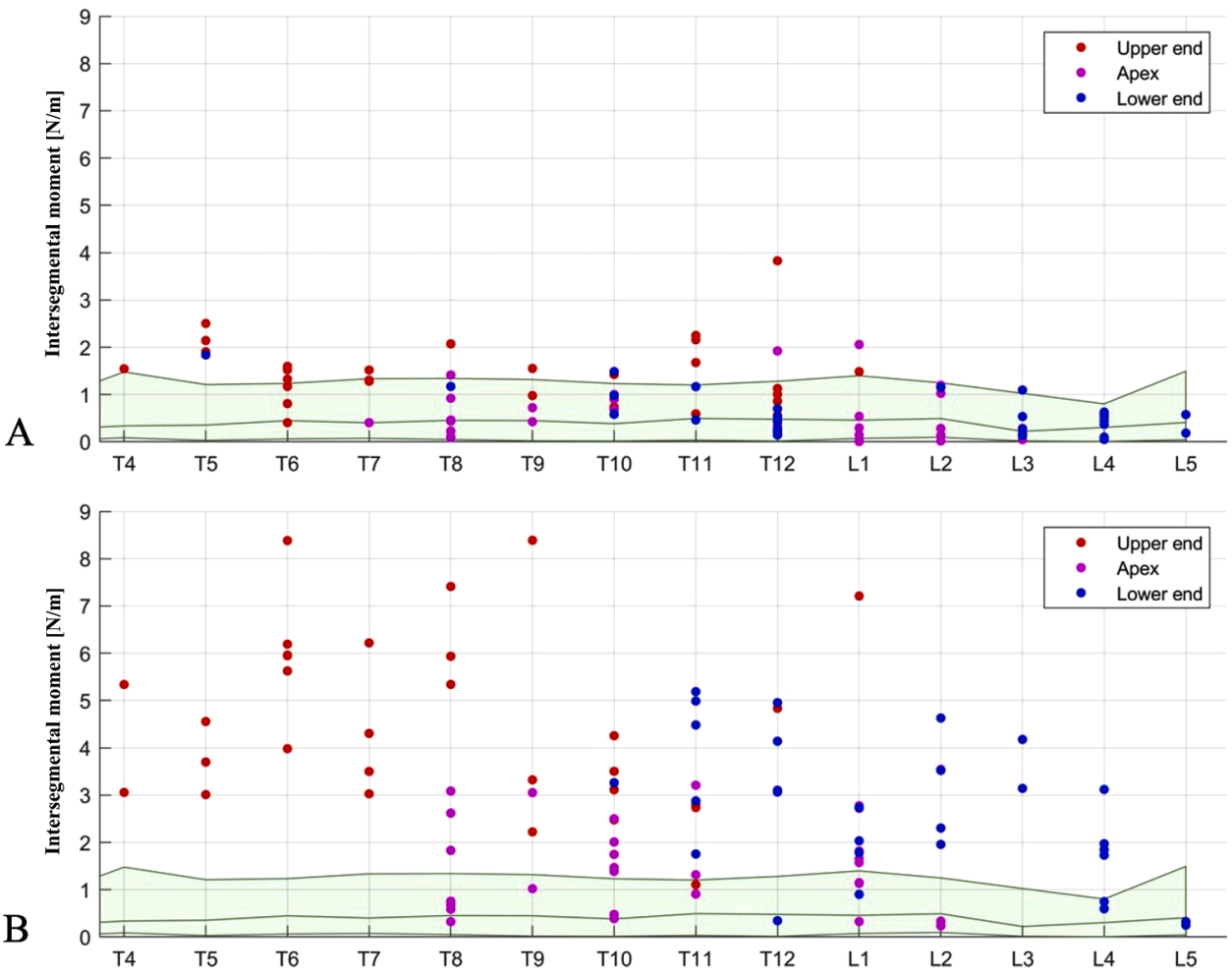

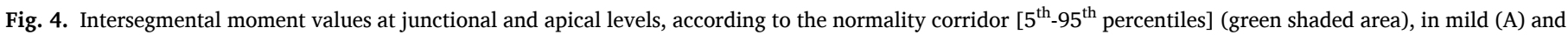
severe scoliosis (B). 

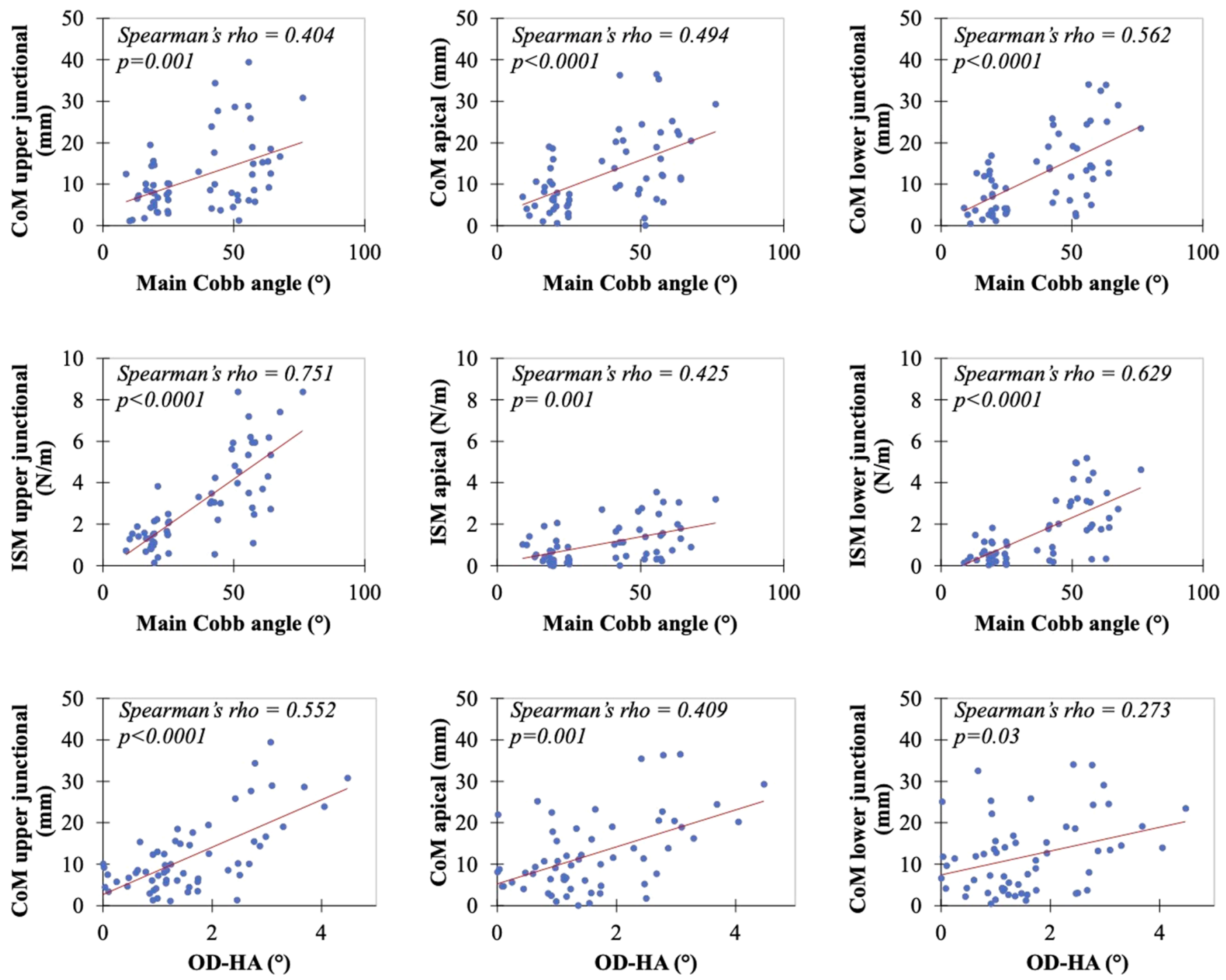

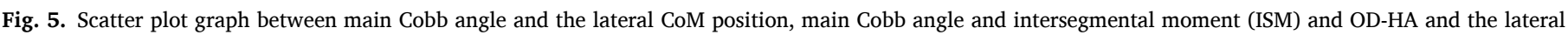
CoM position parameters.

their good compensating mechanisms.

It was interesting to notice that the upper junctional intersegmental moment is higher in scoliotic patients than in asymptomatic controls. We found that $68 \%$ of scoliosis patients had an upper junctional intersegmental moment above 95th of normality corridor. This factor is also a good indicator of severity as $97 \%$ of severe patients was above the 95th of normality corridor. These results confirm the findings about the upper junctional intersegmental moment in the study of Thénard et al. [6]. Perdriolle [17] had reported, on his clinical experience, that the intervertebral torsion of the upper junction level was an important factor in the vicious cycle leading to progression. The present results are consistent with his findings but require further study to confirm them. $40 \%$ of mild scoliosis showed an abnormal upper junctional intersegmental moment. Future work may focus on the relevance of this factor in helping to identify progressive scoliosis at an early stage.

Indeed, an important point is the potential link between the intersegmental moment and the biomechanical disturbance of the intervertebral disc and vertebrae. Larouche Guilbert et al. showed that intervertebral efforts (medio-lateral and antero-posterior) are larger in the adolescent with idiopathic scoliosis compared to the healthy adolescent, except for the axial intersegmental moment [18]. Adam et al. [19] had concluded in preliminary biomechanical analysis about eight idiopathic scoliosis that the gravity-induced intersegmental moment is a likely cause of intravertebral rotation in progressive idiopathic scoliosis. However, the intersegmental torque that was estimated in this work does not necessarily reflects the actual loading of the disc; as Pomero et al. [20] suggested through musculoskeletal modelling, the intersegmental moment is related to musculo-tendon forces and translates into disc compression and shear. Thus, intersegmental moment in this work should be considered as a biomarker reflecting the position and orientation of the vertebra, as well as the position and asymmetry of the mass above it.

The third relevant finding is that the values of the lateral CoM position are higher for thoraco-lumbar and lumbar scoliosis. Once again, this objectively reflects the fact that these curvatures cause greater postural imbalance. In the future, these quantitative factors could be considered in the assessment of a treatment for thoraco-lumbar or lumbar scoliosis.

In our study, we also reported values for the studied parameters (i.e. intersegmental moments, CoM position and coronal trunk balance) in a cohort of 41 healthy individuals with a mean age of 21 years. Blondel et al. [21] described a method of measuring intersegmental moments in a healthy 30-year-old patient. We found almost similar values in the upper thoracic and lower lumbar regions. However, our values were significantly lower in the thoracolumbar region. Larouche Guilbert et al. [18] found intersegmental moment values of the same order of 
magnitude and with the same distribution across levels as our study. For the CoM position and the external envelope analysis we did not find similar results.

The three-dimensional analysis method is accessible to the physician. Bone reconstruction is quasi automatic, taking less than 5 minutes and with good reliability of measurements [3]. On the other hand, the external envelope analysis is still a manual reconstruction method requiring about twenty minutes. Its automation is under development. Nevertheless, 3D assessment of barycentremetry and external shape may provide guidance to the physician in the diagnosis and monitoring of idiopathic scoliosis. First of all, it provides objective and reliable information on the severity of the bone curvature, but also on the imbalance and its disturbances in the axial plane. Other minimally invasive methods of analysis have focused on the external envelope analysis. Jaremko et al. [22] showed that the $360^{\circ}$ torso asymmetry indices developed show a strong relationship between the surface and the spine in scoliosis (the Cobb angle is estimated from the torso indices to within $5^{\circ}$ in $65 \%$ of patients and to within $10^{\circ}$ in $88 \%$ ) with minimal radiological radiation. However, Patias et al. [23] cautioned that the analysis of these different indices in the literature has divergent characteristics in terms of observer-induced error, accuracy, sensitivity and specificity. Recently, Bolzinger et al. [24] proposed a new analysis method for monitoring curvature progression by analysis using surface topography. This analysis allows to differentiate patients with or without increased Cobb angle with a good reproducibility (ICC: 0.816 ) and has allowed to decrease the number of radiographs by $30 \%$.

The findings of our study might help the question we can address is whether a good correction of the lower intersegmental moment will spare the underlying disc degeneration, or if the correction of the imbalance reflect the patient's satisfaction after a specific treatment, or even to assess the position of the axial center of mass in relation to various brace or instrumentation. This study has certain limitations. EOS biplanar X-ray system is limited to $34 \mathrm{~cm}$ in width for the radiographic acquisition. All patients whose contours on the front and lateral view were missing were excluded from the study. Nevertheless, this technical constraint is less frequently encountered in a pediatric population. Another limitation is the position of the arms, which was not standardized for each patient. This could disturb the contour marking of the external shape and has a known effect on the mass distribution [25]. However, a standardized free-standing position was adopted in the study, and the radiographs were excluded if the position was not correct. Our group of asymptomatic subjects mostly consisted of young adults with an average age of 21 years. A cohort of age-matched asymptomatic adolescent was difficult to recruit for this research study. Indeed, ethical standards will enable us to perform biplanar radiography in healthy children. The asymptomatic cohort could be continued with younger subjects in order to improve the corridor of normality. On the other hand, we have deliberately excluded scoliosis between 25 and $35^{\circ}$ to limit potential measurement bias and to clearly differentiate between mild and severe scoliosis. Results of barycentremetry and external shape analysis in idiopathic scoliosis are promising. The intersegmental moment, the center of mass position and the coronal trunk balance parameters appear to be relevant in characterizing the 3D deformity of adolescent idiopathic scoliosis. The upper junctional intersegmental moment seems to be able to distinguish the different stages of curvature severity regardless of curve's location. These findings on biomarkers need to be further investigated, but they could be helpful to the physician in monitoring idiopathic scoliosis, in predicting progression and in assessing treatment outcomes.

\section{Ethical approval}

Parents or adults signed informed consent, which was approved by the national ethics committee (C.P.P. Ile de France VI 6001).

\section{Declaration of Competing Interest}

Conflicts of Interest: R.Vialle declare relationships (grants) with the following companies: Stryker, Nuvasive. T.Langlais, C.Vergari, G.Rougereau, L.Gajny, A.Assi, I.Ghanem, J. Dubousset, R.Pietton, W.Skalli declare no relationships with any companies, whose products or services may be related to the subject matter of the article.

\section{Acknowledgement}

The authors are grateful to the BiomecAM chair program on subjectspecific musculoskeletal modelling (with the support of ParisTech and Yves Cotrel Foundations, Société Générale, Covea and Proteor).

\section{References}

[1] Coonrad RW, Murrell GA, Motley G, Lytle E, Hey LA. A logical coronal pattern classification of 2,000 consecutive idiopathic scoliosis cases based on the scoliosis research society-defined apical vertebra. Spine (Phila Pa 1976) 1998;23:1380-91. https://doi.org/10.1097/00007632-199806150-00016.

[2] Skalli W, Vergari C, Ebermeyer E, Courtois I, Drevelle X, Kohler R, et al. Early detection of progressive adolescent idiopathic scoliosis: a severity index. Spine (Phila Pa 1976) 2017;42:823-30. https://doi.org/10.1097/ BRS.0000000000001961.

[3] Vergari C, Gajny L, Courtois I, Ebermeyer E, Abelin-Genevois K, Youngwoo K, et al. Quasi-automatic early detection of progressive idiopathic scoliosis from biplanar radiography: a preliminary validation. Eur Spine J 2019;28:1970-6. https://doi. org/10.1007/s00586-019-05998-z.

[4] Hong A, Jaswal N, Westover L, Parent EC, Moreau M, Hedden D, et al. Surface topography classification trees for assessing severity and monitoring progression in adolescent idiopathic scoliosis. Spine (Phila Pa 1976) 2017;42:E781-7. https://doi. org /10.1097/BRS.0000000000001971.

[5] Hernandez T, Thenard T, Vergari C, Roblichon L, Skalli W, Vialle R. Coronal trunk imbalance in idiopathic scoliosis: does gravity line localisation confirm the physical findings? Orthop Traumatol Surg Res 2018;104:617-22. https://doi.org/10.1016/ j.otsr.2018.04.018.

[6] Thenard T, Vergari C, Hernandez T, Vialle R, Skalli W. Analysis of center of mass and gravity-induced vertebral axial torque on the scoliotic spine by barycentremetry. Spine Deform 2019;7:525-32. https://doi.org/10.1016/j. jspd.2018.11.007.

[7] Lenke LG, Betz RR, Clements D, Merola A, Haher T, Lowe T. Curve prevalence of a new classification of operative adolescent idiopathic scoliosis: does classification correlate with treatment? Spine (Phila Pa 1976) 2002;27:604-11. https://doi.org/ 10.1097/00007632-200203150-00008.

[8] Faro FD, Marks MC, Pawelek J, Newton PO. Evaluation of a functional position for lateral radiograph acquisition in adolescent idiopathic scoliosis. Spine (Phila Pa 1976) 2004;29:2284-9. https://doi.org/10.1097/01.brs.0000142224.46796.a7.

[9] Nault ML, Parent S, Phan P, Roy-Beaudry M, Labelle H, Rivard M. A modified Risser grading system predicts the curve acceleration phase of female adolescent idiopathic scoliosis. J Bone Joint Surg Am 2010;92:1073-81. https://doi.org/ 10.2106/JBJS.H.01759.

[10] Gajny L, Ebrahimi S, Vergari C, Angelini E, Skalli W. Quasi-automatic 3D reconstruction of the full spine from low-dose biplanar X-rays based on statistical inferences and image analysis. Eur Spine J 2018;28:658-64. https://doi.org/ 10.1007/s00586-018-5807-6.

[11] Nerot A, Choisne J, Amabile C, Travert C, Pillet H, Wang X, et al. A 3D reconstruction method of the body envelope from biplanar x-rays: evaluation of its accuracy and reliability. J Biomech 2015;48:4322e6. https://doi.org/10.1016/j. jbiomech.2015.10.044.

[12] Amabile C C, Choisne J, Nérot A, Pillet H, Skalli W. Determination of a new uniform thorax density representative of the living population from 3D external body shape modeling. J Biomech 2016;49:1162-9. https://doi.org/10.1016/j. jbiomech.2016.03.006.

[13] Duval-Beaupère G. Les repères de maturation dans la surveillance des scolioses [maturation indices in the surveillance of scoliosis]. Rev Chir Orthop Reparatrice Appar Mot 1970;56:59-76.

[14] Duval-Beaupère G. Rib hump and supine angle as prognostic factors for mild scoliosis. Spine (Phila Pa 1976) 1992;17:103-7. https://doi.org/10.1097/ 00007632-199201000-00015.

[15] Duval-Beaupère G, Schmidt C, Cosson P. A Barycentremetric study of the sagittal shape of spine and pelvis: the conditions required for an economic standing position. Ann Biomed Eng. 1992;20:451-62. https://doi.org/10.1007/ BF02368136. 
[16] Legaye J, Duval-Beaupere G. Gravitational forces and sagittal shape of the spine. Clinical estimation of their relations. Int Orthop. 2008;32:809-16. https://doi.org/ 10.1007/s00264-007-0421-y.

[17] Perdriolle R. La scoliose: son étude tridimensionnelle. Paris: Maloine; 1979.

[18] Guilbert ML, Raison M, Fortin C, Achiche S. Development of a multibody model to assess efforts along the spine for the rehabilitation of adolescents with idiopathic scoliosis. J Musculoskelet Neuronal Interact 2019;1(19):4-12.

[19] Adam CJ, Askin GN, Pearcy MJ. Gravity-induced torque and intravertebral rotation in idiopathic scoliosis. Spine (Phila Pa 1976) 2008;15(33):E30-7. https://doi.org/ 10.1097/BRS.0b013e318160460f.

[20] Pomero V, Lavaste F, Imbert G, Skalli W. A proprioception based regulation model to estimate the trunk muscle forces. Comput Methods Biomech Biomed Engin 2004;7:331-8. https://doi.org/10.1080/1025584042000327115.

[21] Blondel B, Pomero V, Moal B, Lafage V, Jouve JL, Tropiano P, Bollini G, Dumas R, Viehweger E. Sagittal spine posture assessment: feasibility of a protocol based on intersegmental moments. Orthop Traumatol Surg Res 2012;98:109-13. https:// doi.org/10.1016/j.otsr.2011.12.001.

[22] Jaremko JL, Poncet P, Ronsky J, Harder J, Dansereau J, Labelle H, Zernicke RF. Indices of torso asymmetry related to spinal deformity in scoliosis. Clin Biomech (Bristol, Avon) 2002;17:559-68. https://doi.org/10.1016/s0268-0033(02)000992.

[23] Patias P, Grivas TB, Kaspiris A, Aggouris C, Drakoutos E. A review of the trunk surface metrics used as scoliosis and other deformities evaluation indices. Scoliosis 2010;29(5):12. https://doi.org/10.1186/1748-7161-5-12.

[24] Bolzinger M, Bernardini I, Thevenin Lemoine C, Gallini A, Accadbled F, Sales de Gauzy J. Monitoring adolescent idiopathic scoliosis by measuring ribs prominence using surface topography device. Spine Deform 2021;29. https://doi.org/10.1007/ s43390-021-00327-1.

[25] Legaye J, Duval-Beaupere G. Influence of a variation in the position of the arms on the sagittal connection of the gravity line with the spinal structures. Eur Spine $\mathrm{J}$ 2017;26:2828-33. https://doi.org/10.1007/s00586-017-4961-6. 